\title{
El papel de los Estados Unidos dentro del conflicto: inicios del siglo XXI
}

\section{Antecedentes: George W. Bush}

Para ubicarnos en la agenda de política exterior de los dos periodos del presidente George Bush, es necesario iniciar con los atentados terroristas del 11 de septiembre de 2001, pues cualquiera que fuese el modelo que pretendía aplicar, este cambió radicalmente. Básicamente, aunque la administración de George W. Bush centró sus objetivos en la denominada «lucha global contra el terrorismo», brindó sin embargo acompañamiento al proceso de negociaciones, bajo la denominada «hoja de ruta».

Durante la administración Bush se concretó la desconexión de Gaza en 2005. Al igual que sus antecesores, Bush hizo un llamado a ambas partes para que continuaran con el proceso de paz, al interior del cual también apoyó la fundación de un futuro Estado palestino. En cabeza del entonces secretario de estado, Collin Powell, estuvo la responsabilidad de lograr un diálogo permanente con Arafat, con quien se reunió en 2002.

La reunión entre Powell y Arafat tenía como objetivo que este último tomase medidas concretas acerca de los avances dentro del proceso de paz, de tal forma que cesara la espiral de violencia que venía azotando la zona. El secretario de estado Collin Powell fue un convencido 
de la necesidad del proceso de paz. Sin embargo, ese periodo fue de los más álgidos del conflicto, con un líder palestino desgastado (Arafat) y uno israelí convencido de que el líder palestino era el obstáculo para concretar la paz (Ariel Sharon).

Durante la administración de George W. Bush, el proceso de paz vio en su desarrollo una serie de cambios que marcaron el rumbo del mismo, tales como la muerte de Arafat, la II Intifada, la construcción del muro fronterizo, la desconexión de Gaza y la llegada de Hamas al gobierno en Gaza. Durante esta administración se vivió un periodo en el que la violencia entre ambas partes creció ostensiblemente y la paz se frustró, así como la reanudación de las negociaciones. Aunque hoy podemos decir que hay una relativa calma en Gaza.

Durante la administración Bush, la política de cooperación de los Estados Unidos dentro del conflicto israelí-palestino quedó plasmada en la denominada «hoja de ruta», la cual «[...] trata de ser un mecanismo basado en el cumplimiento de metas determinadas separadas en tres fases. Israelíes y palestinos deben cumplir requerimientos determinados en forma paralela antes de avanzar» (BBC, 2011).

Con lo anterior se establece, entre otros puntos, que no habrá condiciones previas para avanzar en las negociaciones de paz. La hoja de ruta además nació después de tres años de la llegada del presidente Bush al poder, lo que nos da una idea de lo congelada que estuvo la cuestión israelí-palestina en su primer mandato; dicha hoja de ruta, aunque contó con el apoyo del cuarteto (Estados Unidos, Rusia, Unión Europea y $\mathrm{ONU})$, tuvo también sus detractores, que entre otras razones culpaban a esta administración de diseñar un documento que prácticamente había nacido muerto.

La hoja de ruta, susceptible al aplazamiento y a la evasión por ambas partes, nació muerta. Tras casi cuatro años de su lanzamiento, ninguna de las partes ha logrado reunir la voluntad política necesaria para implementar sus disposiciones principales. Ni siquiera la idea extraña, reservada para la segunda etapa, de crear un Estado palestino con "fronteras temporales" es atractiva para los palestinos. (Proyect Syndicate, 2011). 
El Papel de los Estados Unidos DeNTro del Conflicto: INICIOS DEL SIGLO XXI

Figura 1. Fases del conflicto (2003-2005)

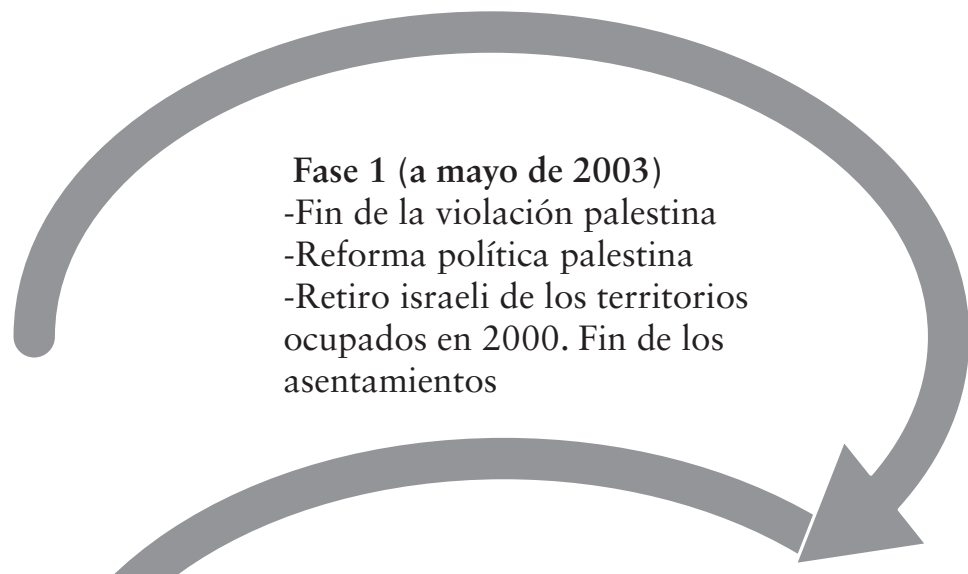

Fase 2 (junio-diciembre 2003)

-Creación de un Estado palestino con

atributos soberanos y fronteras delimitadas.

-Conferencia internacional para verificar

cumplimiento de la fase 2

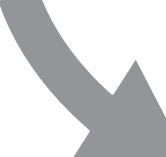

Fase 3 (2004-2005)

-Segunda conferencia internacional.

-El futuro de Jerusalen se discutirá

al final.

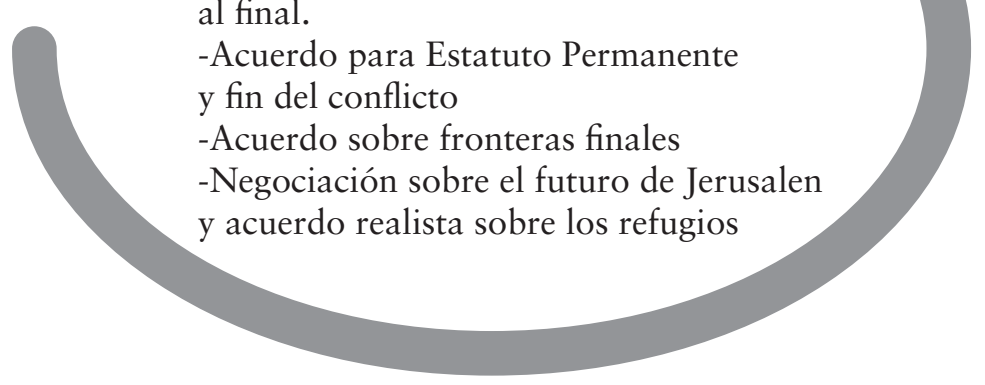

Fuente: elaboración propia. 


\section{La hoja de ruta de George W. Bush}

La estructura básica de la hoja de ruta contenía las fases en las que deberían adelantarse las pretensiones de cada una de las partes, su discusión y viabilidad dentro de unas fechas preestablecidas para concluir con la fundación de un Estado palestino. La búsqueda y materialización de la paz no puede ser objeto de fechas o límites para su consecución, pues al interrumpirse una de esas fechas preestablecidas todo el proceso quedaría en suspenso; esto también sucedió con la hoja de ruta, y decimos también, porque las anteriores propuestas desde la Conferencia de Madrid en 1991 han llevado intrínseca una fecha de expiración de las negociaciones y ninguna ha cumplido este objetivo, por el contrario, frustran una y otra vez las perspectiva de paz en la zona.

Un punto en común de todas las negociaciones de paz entre israelíes y palestinos, que también estuvo en la hoja de ruta, fue el ya desgastado principio de tierra por paz; desgastado porque tal vez en ese momento la AP tenía el control de su propio territorio, a diferencia de lo que ocurre hoy, pues comparte dicho territorio con Hamas y este tiene una agenda muy diferente a la de la AP. Quizá lo innovador de la hoja de ruta fue la propuesta de finalmente reconocer un Estado palestino, con el fin de aliviar la situación en la zona, como ya lo había determinado la resolución 1397 del CSNU.

Sin embargo, este plan tuvo tantos críticos como el proceso mismo. Dichos opositores, con el paso del tiempo, se han convertido en personajes que interrumpen la búsqueda de la paz -en nuestra opiniónpara desviar el curso del proceso con una clara tendencia protagónica. Esto último no conviene a ninguna de las partes involucradas, como tampoco a sus vecinos en la región.

Para algunos críticos de Israel, como el ex ministro Ben-Amí, el conflicto israelí- palestino es «un nudo gordiano que necesita cortarse y no desatarse» (Ben-Amí, 14 de noviembre de 2011), pues ya son décadas de un conflicto de desgaste que no ha avanzado y que por el contrario solo se enreda cada vez más. En su crítica a la hoja de ruta, Ben-Amí da por fracasada la misma con base en que ninguna de las partes ha sido capaz de negociar sin un intermediario, y que por el contrario prefieren extender más este conflicto de desgaste, por cuanto 
ninguno de los líderes involucrados tienen la entereza de propinar cambios políticos, pues se vería afectada su imagen política.

Cualquier proceso de paz reformado está condenado al fracaso si tiene como guía una hoja de ruta en la que en los asuntos esenciales las partes tienen puntos de vista diametralmente opuestos. Pero no hay necesidad de reinventar la rueda porque la solución al conflicto árabe-israelí está plasmada en los planes principales para la paz que ya están sobre la mesa: los parámetros de paz de Clinton y la iniciativa de paz árabe. (Proyect Syndicate, 2011).

Si el plan de paz de Camp David II es el modelo a seguir, quiere decir que para Ben-Ami el proceso iniciado en 2009, al igual que el de esta administración, están equivocados, pues el crítico no cree en la negociación directa o cara a cara. En todo caso, la comunidad internacional vio la hoja de ruta como algo improvisado, pero hemos de recordar que en ese momento los Estados Unidos estaban imbuidos en dos guerras que también terminaron convirtiéndose en guerras de desgaste, solo comparables con la Guerra de Vietnam.

Sin embargo, al igual que antes, las negociaciones se han visto alteradas en parte por la irrupción del grupo terrorista Hamas en el escenario político, de hecho pensamos que se perdieron oportunidades realmente creíbles antes de que Hamas llegara al poder, dada la hostilidad y el poder que este grupo terrorista que gobierna Gaza adquirió, es indudable que el proceso de paz fue complicado durante este periodo, lo ha sido ahora y muy seguramente lo continuará siendo.

El final del bilateralismo proviene también de los sistemas políticos disfuncionales tanto de Israel como de Palestina. Actualmente, el Presidente palestino Mahmud Abbas está jadeando por un respiro político bajo el control asfixiante de Hamas. En su reciente viaje a Israel, Rice tuvo que escuchar cuatro planes de paz diferentes de parte del primer ministro, el ministro de relaciones exteriores, el ministro de amenazas estratégicas y el ministro de defensa. Tanto para los israelíes como para los palestinos, lograr la paz interior 
podría resultar un reto tan imponente como el de establecer la paz mutua. (Ben-Ami, 14 de noviembre de 2011).

A la muerte de Arafat le siguió el nombramiento de Mahmud Abbas como presidente de la ANP. Durante la administración de George W. Bush se creyó que posiblemente se destrabarían las negociaciones y de hecho se llevarían a cabo avances positivos, al final no fue así, ni entonces ni ahora.

También fue traumático para las negociaciones el retiro forzoso del primer ministro Ariel Sharon de la vida política, por causa de su enfermedad -y posterior deceso-, pues el ascenso de Ehud Oldmer al poder no garantizó que su gobierno fuera a avanzar en las negociaciones, por el contrario, fue él quien ordenó la Operación Plomo Fundido sobre Gaza que vino a la postre a causar uno de los mayores deterioros de la imagen de Israel a nivel internacional. Durante este periodo, incluso Siria propuso su propio plan de paz, que incluyera no solo a los palestinos sino a sí misma, lo que vendría a representar un atraso al ya desgastado proceso entre israelíes y palestinos. La cuestión pendiente de resolver del Golán es claramente otro conflicto que no afecta a los palestinos, por lo tanto, es lo que podríamos llamar un proceso aparte.

Del mismo modo, quienes propusieron la iniciativa de paz árabe de 2002, entendieron que un enfoque estrictamente bilateral podría ser insuficiente, y en cambio pidieron que se regionalizara la solución al conflicto. La pérdida mutua de confianza entre las partes, y su completa incapacidad para tomar las medidas mínimas para acercarse, ya no se diga para cumplir sus compromisos sin la intervención de terceras partes, hizo (y todavía hace) que la única salida del peligroso impase sea un marco internacional para la paz. (Ben-Ami, 14 de noviembre de 2011).

El reconocimiento de Ben-Ami de la iniciativa de paz de 2002, propuesta por los Estados árabes, a todas luces es un punto que retrasa aún más la resolución del conflicto y un acuerdo de paz, pues ya no solo se trata de solucionar el tema palestino, sino que además se adiciona la 
cuestión del Golán con Siria. Al respecto, creemos que las diferencias entre israelíes y sirios deben ser abordadas solo por las partes involucradas, pretender adicionarlo en las negociaciones de paz sería trabarlas más y negar a las dos partes el derecho de avanzar en las mismas.

En la hoja de ruta no fue involucrado el punto sobre el Golán, pues se entiende que este es un conflicto entre partes distintas que debe ser resuelto solo por ellas y en ocasión de unas negociaciones igualmente directas.

Sin embargo, la hoja de ruta gozaba de más generalidades que de puntos concretos, en cuyo caso es posible entender por qué sus críticos afirman que esta nació muerta, pues lo mismo sucede con la agenda de la administración Obama. En este caso, es incoherente que quien funge como mediador sea también quien imponga la solución. El carácter general del proyecto no generó confianza ni siquiera entre las partes, mucho menos en los observadores externos a las negociaciones, y es que no es posible diseñar un proyecto de búsqueda de la paz que está estructurado sobre unas bases débiles en su fondo y en su forma.

Una de las generalidades incluidas, y que menos aportan al avance de la solución del conflicto y la búsqueda de la paz, no es otra que las denominadas Conferencias Internacionales. Está demostrado que estas no contribuyen a la solución del conflicto, ni siquiera a su avance; por el contrario es otro punto que retrasa, por eso insistimos en la necesidad de generar un cara a cara o diálogo directo, ya que son las partes implicadas las que conocen la realidad del conflicto sobre el terreno.

A partir de la Conferencia de Madrid en 1991, -ella incluida-, no conocemos ningún resultado concreto, óptimo, sólido de avance en las negociaciones. Incluso el proceso de Oslo, que fue el que se pensó más creíble, ha sido prácticamente desmantelado por ambas partes, pues una de las bases o la base principal sobre la que se estructuró fue el principio de tierra por paz, actualmente desmantelado y poco creíble; éstas concluyen generalmente en una declaración de intenciones, pero que a la postre no aportan grandes avances a la solución del conflicto israelí-palestino, las partes lo saben, como también lo saben los estudiosos del tema y sus sociedades.

Anteriormente mencionamos que la razón básica de que el conflicto tuviese poco eco al principio de la administración Bush fue la 
guerra global contra el terrorismo, de tal forma que en ese periodo el gobierno de Sharon construyó el muro fronterizo, no sin recibir críticas desde distintas organizaciones multilaterales, como la proveniente del Tribunal Internacional de Justicia (TIJ):

Israel está obligado a poner fin a sus incumplimientos del Derecho internacional; está obligado a interrumpir inmediatamente los trabajos de construcción del Muro que edifica entre los Territorios Ocupados palestinos, incluido Jerusalén Este y sus alrededores, y a desmantelar de manera inmediata las estructuras allí establecidas. (Alvaraz, 2005).

La construcción del muro debilitó en ese momento la ya deteriorada imagen de Israel ante la comunidad internacional que, según algunos críticos, hace parte del proyecto de hechos consumados por parte de Israel para dificultar las negociaciones de paz o para negociar sobre lo ya existente. De igual forma, los palestinos también perdieron ante la comunidad internacional durante la II Intifada, pues no se vio esta con el mismo lente con que se vio la primera en 1987, esta última no fue aquel levantamiento de piedras y palos de la primera, en consecuencia el mensaje recibido en el exterior no llegó de igual forma que en 1987.

Tal vez, uno de los aspectos que más ha dificultado la búsqueda y consecución de la paz, durante los distintos periodos de negociación de un conflicto de desgaste como este, ha sido la mediación de los Estados Unidos. Esto ha dado lugar a que en las últimas décadas algunos países de Europa asuman una posición que no favorece la resolución del conflicto.

Se da por un hecho consumado que la posición de los Estados Unidos como mediador en el conflicto es a favor del Estado de Israel. En mi opinión, este es un equívoco que solo provoca daño a la búsqueda de la paz. Los gobiernos de Jimmy Carter y Bill Clinton son la prueba de la neutralidad, ambos lograron sendos acuerdos que significaron cambios en la región. 
Algunas desafortunadas intervenciones en el conflicto, durante la última década, han sido las del exministro español de exteriores, Miguel Ángel Moratinos:

Una vez agotadas las expectativas creadas con la llegada del gobierno laborista de Ehud Barak y tras la falta de acuerdo a pesar del compromiso activo del presidente Clinton, se hicieron patentes los límites del "sacrosanto" modelo de la paz americana $[. .$. Cambiar la metodología del trabajo e intentar compartir la pesada carga de la mediación en Oriente Próximo con otros actores internacionales [ya que] la realidad nos ha demostrado que la participación de Estados Unidos es esencial, pero en ningún caso suficiente. (El País, 2005).

Tanto la hoja de ruta como las anteriores propuestas han sido debatidas y en ocasiones apoyadas por la comunidad internacional, por el mediador y las partes, por lo que, ampliar más el entorno de la negociación no ha sido de gran ayuda en la búsqueda de la paz entre israelíes y palestinos. En ocasiones la participación de la Unión Europea (UE) es bastante difusa, por ejemplo, las intervenciones de Bernard Kushner o el exministro Moratinos no sirvieron de ayuda para lograr el consenso de las partes respecto a la necesidad de regresar a las negociaciones en su momento. Este tipo de actitudes nos lleva a preguntarnos ¿quién es el representante de la UE dentro del conflicto? ¿Es uno solo o varios?

El conflicto, aun con su complejidad, no debe ser utilizado como una cuestión de los Estados Unidos contra Europa, como la han hecho en ocasiones políticos europeos como los ya mencionados. Esta situación ha causado que las partes se identifiquen unos con uno u otro lado del Atlántico, lo que ha perjudicado grandemente las negociaciones de paz. En tanto que los israelíes se identifican con la posición estadounidense dentro del conflicto, los palestinos miran a Europa como la protectora de su posición ante los Estados Unidos, esta dinámica lejos de acercar aleja el consenso. 
La participación de los Estados Unidos y su cooperación, en cierta forma, está legitimada en que las partes confían en él, no solo por su posición a nivel global, que en efecto dista del resto del mundo, sino también porque ha demostrado que aunque una de las partes comparta valores culturales y políticos con el mediador, de igual forma ha mantenido una estrecha relación de cooperación con la otra parte, al punto de participar de la ayuda al desarrollo de la misma. A esta situación hay que adicionar la desconfianza de los israelíes hacia la participación europea dentro de las negociaciones; no hay que olvidar que esta desconfianza proviene de su propia historia, para ser más exactos, del Holocausto, que partió en dos la historia judía. En síntesis la participación de la UE en este conflicto es una situación bastante ambigua, pues no en pocas ocasiones hemos observado el apoyo incondicional de Alemania hacia el Estado hebreo en los foros y organizaciones multilaterales, pero no se observa lo mismo en otros países de la Unión Europea.

La historia de Israel, unida a lo que su existencia significó y significa para los palestinos, está antecedida por el Holocausto judío, esta es también una de las razones que han llevado al Estado hebreo a invocar su seguridad como primera condición para la paz. La seguridad de un Estado como Israel -en el que su posición geográfica lo sitúa cuando menos cercano territorialmente a gobiernos hostiles, como es el caso de Irán- debe ser un punto estrictamente garantizado dentro de las negociaciones.

Propender por la existencia de su Estado es un fin al que ambos pueblos tienen derecho en igualdad de proporciones. Además, no se debe olvidar la presión que se vive a uno y otro lado del conflicto, y que debe resolverse sin intervenir para hacer contraposición a una de las partes sino para lograr el consenso entre estas y en lo posible lograr la continuidad de las negociaciones de paz. Es necesario invitar a los palestinos a formar una democracia y a los Israelíes a participar en la integración de su país en la región, más allá de los líderes de su gobierno. 


\section{Barack Obama: 2009-2011-2016}

La llegada de Barak Obama a la Casa Blanca suscitó un grueso interrogante para el Estado de Israel, principalmente para el primer ministro Benjamín Netanyahu, pues el apoyo recibido por la comunidad judía de los Estados Unidos a la candidatura demócrata no se tradujo en los resultados esperados por esa comunidad y mucho menos por Israel. Con el precedente de una relación inmejorable en tres de los cuatro periodos presidenciales anteriores, los Estados Unidos empezaba a dar un giro estratégico nunca imaginado: George W. Bush había sido firme aliado de Israel, así como Bill Clinton lo fue tanto o más que su sucesor, al punto que es conocido como el presidente estadounidense más pro Israel de la historia.

Los predecesores del presidente Obama colaboraron realmente en la búsqueda de la paz, de una manera imparcial y sin presionar solo a una de las partes. Tanto Bush como Clinton, en su momento, propendieron por sendos esfuerzos de paz con miras a la resolución del conflicto, pero ninguno de los dos adoptó una posición a favor de alguna de las dos partes, es decir, nunca propendieron por satisfacer el deseo de una de las partes ni al mundo árabe, ni al mundo judío, por lo que el proceso de paz de Camp David II fue lo más cerca que se ha estado a la firma de la paz.

Durante el primer año de la administración Obama el tema del conflicto israelí-palestino estuvo prácticamente aparcado, pues el nuevo presidente desarrolló una política internacional que se limitó casi exclusivamente a las relaciones con Europa y el mundo musulmán. Del nuevo hito de la política internacional se esperaba que al momento de abordar el conflicto lo hiciera incluso con cierta simpatía hacia los israelíes, debido a que su gabinete estaba plagado de figuras judías representativas de la política interna estadounidense, tales como Ben Bernanke, entonces secretario del tesoro; Ram Emmanuel, entonces secretario general de la Casa Blanca, entre otros.

Después del discurso del presidente Obama en la Universidad de El Cairo, hemos visto en los medios de comunicación internacionales columnas que hablan del cisma de las relaciones entre los históricos aliados. Del mismo modo, la presión ejercida contra Netanyahu, 
antes y durante los primeros diálogos de paz en septiembre de 2010, fue captada por la información mundial; así, por ejemplo, se habló de una fisura histórica y de que Israel ya no era el preferido de la Casa Blanca. El primer golpe a las que serían las nuevas relaciones fue la elección de Benjamín Netanyahu como nuevo primer ministro de Israel y por consiguiente la contundente victoria de un nuevo estilo de gobierno en Israel, partidos políticos antes insignificantes y sin mayor representación decisoria en el Knesset (parlamento) fueron votados con amplias mayorías, tal fue el caso de Israel Beitenu††

Uno de los primeros pasos que dio el Presidente Obama, mediante el que quería cambiar ya dejar cierta semilla de lo que sería su futura política, fue el discurso pronunciado el 4 de junio de 2009 en la Universidad Al-Azhar, de El Cairo. En un afán de estrechar lazos con el mundo musulmán, y señalando que a pesar de que él fuera cristiano proviene de una familia de Kenia con generaciones de musulmanes en su seno, desea luchar contra los estereotipos negativos del Islam allí donde surjan [...] Dicho esto, Obama dejo claro que lo que había que afrontar es el extremismo violento, en todas sus formas, y eso no significaba estar en Guerra con el Islam. (Bermejo, 2011).

La primera visita del presidente de los Estados Unidos a Oriente Medio no fue a Israel sino a Egipto. En su discurso en la Universidad de El Cairo el presidente Obama afirmó: «el Islam es la religión de la paz». Dicha afirmación fue suficiente para despertar reticencias en la coalición de gobierno israelí, que se cerró en su posición dentro de las negociaciones de paz. Esta administración estadounidense ha chocado constantemente con la concesión de pretensiones a los palestinos dentro de la negociación, ya que el gobierno israelí se niega a ceder a las pretensiones palestinas.

Históricamente los presidentes estadounidenses habían afirmado: «nuestro apoyo a Israel es inquebrantable», y el presidente Obama no fue la excepción. No obstante, con el discurso de El Cairo no consiguió lo que sus predecesores sí consiguieron, y fue que el gobierno de 
Israel sintiera confianza por su aliado. Cada frase dirigida hacia los palestinos fue una confirmación de la ruptura que se había originado entre ambos gobiernos, pues desde Israel se sintió distancia hacia su gobierno. Sin embargo, el nuevo presidente tuvo claro que él iría más allá que sus predecesores en la negociación, al afirmar lo siguiente:

Han sufrido la búsqueda de una patria, durante más de sesenta años han sufrido el dolor de su deportación [...] Así que no dejemos ninguna duda al respecto: la situación del pueblo palestino es intolerable. Estados Unidos no dará la espalda a la legítima aspiración Palestina a su dignidad, sus oportunidades y un Estado propio. Desde este prisma, el camino que proponía es conocido: dos Estados, en los que tanto israelíes como palestinos vivan en paz y seguridad. (Bermejo y Pozo, 2011, p. 346).

Las consecuencias de este discurso fueron, entre otras:

1) El discurso de El Cairo representó efectivamente un cambio del cual hoy tenemos los resultados: a) la autoridad palestina interpretó que había llegado la oportunidad de dar un gran salto, pues ningún otro presidente estadounidense había llegado tan lejos en un discurso plagado de simbolismo para el mundo árabe. En ese sentido, los palestinos detectaron un giro en la tradicional alianza protectora Israel-Estados Unidos y lo utilizaron, desde entonces, como punto de presión más frente a los Estados Unidos que hacia el gobierno de Israel.

Esta situación ha sido aprovechada por Abbas frente al presidente Obama, el cual ha visto revertirse su discurso de El Cairo, contra sí mismo y contra la política exterior, en forma de deterioro del liderazgo estadounidense para mediar en el conflicto. Hoy la AP -como no había ocurrido antes- libra un pulso diplomático contra la posición de los Estados Unidos en la resolución del conflicto, cuestión que ha presionado el uso del veto en el Consejo de Seguridad de Naciones Unidas por parte del Presidente Obama.

El discurso de El Cairo, en cuanto al sentimiento israelí, se puede interpretar desde la óptica del desplazamiento de su propio discurso históricamente reivindicatorio como Estado ahora a favor de su 
contradictor, más aún, quien desplaza su discurso es su propio aliado. Los judíos sufrieron no solo la deportación sino el exterminio (que no ha sufrido el pueblo palestino), luego libraron una lucha en Jerusalén contra los árabes, sin la ayuda de los Estados Unidos. Solo al final, y después de una larga y sangrienta guerra en Jerusalén, el presidente Truman se compromete con Chaim Weizman a apoyar a Israel en Naciones Unidas. La mención, por parte del presidente Obama, de la situación en Gaza y la presunta crisis humanitaria, fue otro duro golpe a la política israelí de bloqueo de esa frontera, pues su gobierno siempre ha defendido el bloqueo como solución al tráfico de armas por parte de Hezbollah y de otros grupos terroristas con destino a Hamas.

Recientemente la representante de la Cruz Roja Internacional en Gaza, Mathilde Redmatn, manifestó:

Si vamos al supermercado encontramos todo tipo de productos. Hay restaurantes, una playa primorosa, problemas como en todas partes, de infraestructura y para el suministro de cemento. Israel tiene el derecho legítimo de proteger a su población civil, ese derecho debe ser medido con el derecho de 1,5 Millones de personas en la franja de Gaza. (AJN, 2008).

2) La segunda consecuencia del discurso de El Cairo, en el cual los Estados Unidos perdieron liderazgo y que animó a la AP a desafiarlo, fue la denominada «Primavera Árabe», en la que parece ser que la participación estadounidense fue nula. El nuevo escenario en Túnez y entonces en Egipto impulsó a los palestinos a llevar a cabo su propia "primavera diplomática», de tal forma que han acudido al máximo escenario posible que involucra a la comunidad internacional en su totalidad, representada en la Asamblea General, con el fin de que los Estados Unidos sientan la presión internacional y sean ellos quienes carguen con la culpa de la no existencia de un futuro Estado Palestino.

El desequilibrio que el presidente Obama causó con su constante discurso de lo que sus críticos denominan complacencia con el mundo musulmán, ha sido entendido por la AP como un espacio desde el que se genera una fuga, esa fuga no es otra que la política de los 
Estados Unidos frente al proceso de paz. El discurso sistemático acerca de la exculpación del Islam, por parte del presidente Obama, ha sido el punto flaco de su política exterior en la zona. La complejidad se acentúa aún más en la posible resolución del conflicto a la que todos le apostaban con el nuevo presidente de los Estados Unidos. En el conflicto israelí-palestino continuamente se ha pecado por dos aspectos: 1) creer que es una cuestión de color político, 2) poner fecha a la resolución del mismo y 3) la falta de continuidad de un proyecto único y a largo plazo.

\section{Tres errores fundamentales al interior del conflicto}

En mi opinión, se han cometido tres errores al interior de las negociaciones de paz del conflicto israelí-palestino que han impedido el avance de las mismas. Extrañamente, en 2012 el denominado cuarteto volvió a caer en ellos. Dada la situación cambiante de este conflicto, incluida la última y tal vez más álgida entre las partes y el mediador, este exige de los garantes una visión holística, de tal forma que no se caiga en los errores del pasado, evitando al máximo deteriorar más el escenario y poner trabas a la solución. Estos tres errores son:

\section{Creer que es una cuestión de partidos políticos}

La larga lista de ocasiones en que la que los Estados Unidos y los líderes israelíes y palestinos se han reunido, en busca de una resolución del conflicto, muestra que la cuestión imperante ha sido la voluntad política y no el partido político de turno en el gobierno estadounidense. Sin embargo, el error aquí suele provenir del interior de los Estados Unidos, donde no pocas críticas argumentan que la política exterior estadounidense hacia Israel está en manos de los grupos de presión pro-israelíes, por lo que adjudican una carga ideológica que solo arriesga los posibles adelantos en la gestión del conflicto. Así, en la campaña presidencial 2008 enconados críticos del Estado de Israel daban por descontada la unívoca política estadounidense dentro de 
las negociaciones de paz, sin embargo no faltaron posiciones ideológicas, tales como:

Esto no significa que no existan sutiles diferencias subyacentes entre Obama y MacCain, o incluso entre ellos y la gestión de la administración Bush. Obama fue el único candidato que mostraba en su pasado cierto entendimiento de los temas que enfrentan a ambos bandos en el conflicto. Antes de convertirse en candidato a la presidencia, Obama recordó al público en su discurso que el partido Likut de extrema derecha no es sinónimo del Estado de Israel. Más de una vez había comentado que los palestinos figuran entre "los pueblos más oprimidos de la tierra" y que las preocupaciones palestinas requieren que se afronten con justicia e imparcialidad. (Matthews, 2008).

La carga ideológica que se aplique por parte de los Estados Unidos dentro del conflicto puede llegar a destruir la posibilidad de una resolución satisfactoria para ambas partes. Bajo este panorama, es importante la neutralidad del mediador para no permitir que esto ocurra por parte de demócratas y republicanos o de críticos intelectuales de uno y otro lado, no solo por la congelación de la negociación, que ya de por sí trae efectos funestos, sino por las consecuencias sobre el terrero. Existe la voluntad política, porque existen unos intereses y la convicción de que el conflicto no arrastre más violencia en la zona de la que ya ha generado durante sesenta y cuatro años. Tomemos como ejemplo las dos administraciones anteriores a la del presidente Obama: el entonces presidente Bill Clinton se reunió en Camp David con el primer ministro Ehud Barak y el líder palestino Yasser Arafat; de igual forma, el presidente George W. Bush se reunió en Anápolis con el primer ministro Ehud Olmert y el presidente de la ANP Mahmud Abbas.

La voluntad política de los presidentes de los Estados Unidos, además de notoria, ha sido una responsabilidad compartida. Por ejemplo, yendo a espacios más amplios de la negociación, podemos mencionar la conferencia de Madrid en 1991 o los Acuerdos de Oslo en 1993, pese a que ambos casos fueron protagonizados por distintos partidos 
políticos, tuvieron la máxima voluntad política. Se incurre en un error cuando se piensa -desde ámbitos ajenos a la política- que los Estados Unidos algunas veces tienen voluntad política y otras no; tampoco es viable creer que desde el ámbito político internacional se puede estigmatizar a demócratas o republicanos por los fallidos resultados de la negociación.

No depende, entonces, de que el presidente de turno pertenezca a un partido u otro, pues los Estados Unidos han demostrado siempre su voluntad política, indistintamente de colores políticos o ideologías $y$, precisamente por esa voluntad inquebrantable de implicarse en el tema, se considera el único interlocutor fiable para participar de la resolución del conflicto. Ya otras latitudes políticas pueden generar más fisuras en el proceso, por ejemplo, Europa o Rusia pudieran llegar a complicar la situación.

\section{Delimitar la fecha de la solución del conflicto}

En esta ocasión, como en administraciones anteriores, se ha incurrido constantemente en el error de fijar fecha límite a la consecución de la paz en la zona. Recientemente, después de que la autoridad palestina expusiera su propuesta de Estado de pleno derecho ante Naciones Unidas, el denominado Cuarteto para Oriente Medio volvió a incurrir en el mismo error del pasado.

Al reducirse la capacidad de maniobra de Estados Unidos, los europeos han ocupado el centro de la acción diplomática en la ONU y han sido foco de atención por parte de israelíes y palestinos. En Nueva York, la UE ha utilizado el Cuarteto para Oriente Próximo para impulsar las conversaciones de paz y tratar de buscar una alternativa al reconocimiento del Estado palestino. La alta representante para la Política Exterior de la UE, Catherine Ashton, ha utilizado sus herramientas de "diplomacia silenciosa" para fijar el calendario y los términos de futuras negociaciones y ha trabajado entre bastidores para proponer una alternativa a la adhesión de Palestina como miembro de pleno derecho. El Cuarteto ha adoptado 
una agenda de seis puntos que debería concluir en 2012 con la firma de un acuerdo de paz entre las partes. (Morillas, 2011).

Durante la conferencia de Annapolis en 2007, el presidente Bush cometió el mismo error. Decimos que es un error porque la paz no es susceptible de fechas impuestas, ya que esto supondría limitar el calendario del proceso para conseguir un acuerdo a como dé lugar, por el simple hecho de cumplir con dicha fecha. Durante las negociaciones suelen surgir obstáculos que pueden ocasionar retrasos por culpa de una de las partes o incluso de ambas. También debe tenerse en cuenta que hay factores externos que pueden llegar a afectar la negociación, por ejemplo, la división existente entre los palestinos o el grupo terrorista Hamas como un factor externo a la negociación que puede influir para bloquear la misma.

Estamos de acuerdo en lanzar las negociaciones bilaterales de buena fe para llegar a un acuerdo de paz. Estamos convencidos de que hay que trabajar vigorosamente y hacer los esfuerzos para llegar a un acuerdo de paz antes del fin de 2008, ha dicho Bush en un discurso ante los representantes de 40 países y organizaciones que han participado en la histórica cumbre. (Morillas, 2011).

Supeditar la paz a una fecha determinada es, al mismo tiempo, generar una caducidad inmersa en la misma negociación, pues si no se consigue en dicha fecha las partes podrían alegar este efecto para retirarse de la negociación. El proceso de paz israelí-palestino es hoy un proceso de desgaste y los límites que se le han impuesto han tenido que ver con esto. De continuarse con las fechas límites no se conseguirá más que seguir afectando la negociación, de tal forma que el mensaje que se recibe es el de un proceso que nace muerto, ya que ante las complejas aspiraciones de las partes no es posible cumplir límites de tiempo. 


\section{Falta de continuidad de un programa de negociaciones}

Este tercer error tiene que ver con la discontinuidad entre una administración y otra, tanto de las partes directamente involucradas como del tercero mediador. Ambas partes tienen por tradición atenerse a la propuesta que cada nueva administración estadounidense esboce después de llegar al poder, lo cual generalmente produce un congelamiento del tema en épocas como la campaña presidencial, pues el conflicto israelí-palestino se convirtió en punto obligado a tratar dentro de la misma.

Con este antecedente, es de esperar que cada cuatrienio el proceso tienda a congelarse, prolongando así la ya desgastada situación que solo perjudica a las partes afectadas. Esta es una de las razones por las que esta investigación plantea que, posiblemente, una salida sólida a este conflicto debe ser necesariamente la negociación directa. La razón para trazar un proyecto a largo plazo es que este conflicto se convirtió en un conflicto de desgaste, interrumpido y en constante mutación, por lo que un cambio de proyecto cada cuatrienio hace más daño que cualquier otro impedimento que surja entre las partes.

Un proyecto a largo plazo no es otra cosa que el diseño de una política de cooperación sin distinción de partido político de ninguna de las partes, ni del mediador. Este debe ser un proyecto consensuado con las partes directamente afectadas, una cronología abierta y no cerrada ( $\sin$ fecha de caducidad), con la participación de la sociedad civil de ambas partes del conflicto, de los representantes de cada gobierno y del mediador, junto con los líderes de las partes que prioritariamente deberán conocer las discusiones. Mediante un proyecto a largo plazo se puede conseguir la transformación del conflicto, de tal forma que con la transformación se consigan atenuar las dificultades más inmediatas de las partes.

El modelo a largo plazo necesitará para su legitimación y garantía un acompañamiento neutral, que le garantice a las partes que ninguna de las dos verá afectados sus intereses más allá de lo que ellas mismas acuerden, de tal forma que esta legitimidad y garantías solo podría estar en cabeza de Naciones Unidas, en la agencia que según sea el caso las partes decidan nombrar. 
El diálogo directo, sin fechas de caducidad y la continuidad son tres pilares fundamentales de primera línea para la búsqueda de la solución del conflicto israelí-palestino. Es evidente que junto a estos deberá existir otros pilares de segunda línea, no menos importantes, que serán subsidiarios dentro de las negociaciones para llegar al consenso de las partes. La confianza sería uno de esos pilares de segunda línea, pues ésta garantizará a las partes, así como al mediador y a la ONU, la neutralidad como garantía en el proceso.

La neutralidad dentro del proceso, no la ubicamos en ninguna línea de los pilares necesarios para el desarrollo del proyecto y la búsqueda de la paz, precisamente por su carácter integrador, receptor y conciliador de la que está imbuido el concepto de neutralidad. Esta es absolutamente necesaria si se piensa en un proyecto a largo plazo que busque la transformación y posterior solución del conflicto israelí-palestino. La neutralidad genera la confianza necesaria para que cada una de las partes sea receptora de las pretensiones de la otra dentro de las negociaciones, además, la confianza permite el avance para llegar a conciliar los puntos en disputa.

\section{Política de cooperación estadounidense dentro del proceso de paz israelí-palestino}

La política de cooperación entre los Estados Unidos e Israel dentro del conflicto está construida a partir de una cooperación institucional entre ambos Estados. En este sentido, no es una cooperación supeditada a los cambios de gobierno en los Estados Unidos ni mucho menos en Israel.

Sin embargo, desde que en 2009 se iniciaran los diálogos de paz en Washington, posteriores a la pública tensión que se vivió entre el presidente de los Estados Unidos y el primer ministro israelí, el 2 de septiembre de dicho año, finalmente se volvió a las negociaciones, a través de una invitación auspiciada por la administración estadounidense. Los diálogos se iniciaron a pocas semanas de concluir el periodo de 10 meses de congelación en la construcción de nuevos asentamientos que había concedido el primer ministro Netanyahu, lo cual anticipaba el fracaso de las negociaciones, como efectivamente sucedió. 
Luego del fracaso en las negociaciones, el proceso se estancó durante más de un año, y, al tratar de resucitarlo, el presidente Obama declaró la necesidad de volver a las negociaciones teniendo como punto de partida las fronteras de 1967 , bajo la premisa de seguridad por territorio, retrotrayendo así a las pretensiones citadas en la Conferencia de Madrid, tal como lo exige la AP como condición previa al regreso a la mesa de negociaciones. Al mismo tiempo, Obama fijaba la cuestión de Jerusalén y de los refugiados para después de concretar el tema de las fronteras.

El error político cometido hacia Oriente Medio, y específicamente hacia el proceso israelí-palestino, ha sido una constante en la política exterior estadounidense del presidente Obama, también ha sido un fracaso de la secretaria de Estado Clinton, que fue vista por la comunidad internacional como alguien capaz de servir de catalizador para garantizar avances positivos dentro de las negociaciones, pues no solo era cercana a la comunidad judía estadounidense sino que también gozaba de una buena reputación entre el círculo político de la AP. Sin embargo, el carisma de la secretaria de Estado y sus buenas relaciones con ambas partes tampoco fue suficiente para lograr un entendimiento entre las mismas en pro de iniciar una negociación fiable.

Los conflictos no se pueden solucionar si quien ejerce de mediador toma partido en la solución. Por el contrario, este mediador se debe comprometer a buscar el equilibrio dentro del conflicto, sin inclinar la balanza a favor de ninguna de las partes, pues deben ser estas últimas quienes tomen las decisiones y decidan sobre la gestión y transformación del conflicto.

El estilo de Lederach parte de que el hilo conductor para la transformación de un conflicto se encuentra ya en la cultura de las partes involucradas y de que el mediador que intermedia en la comunicación entre ellas lo que hace es ayudarlas a que se haga explícito lo que ya implícitamente tienen en su propia cultura. Las mismas partes involucradas han de idear, plantear, decidir y sostener conjuntamente el proceso de solución del conflicto en que están metidas. (Galtung, 2003). 
Dicho de otra forma, la actual política de cooperación de los Estados Unidos dentro del conflicto israelí-palestino ha sido la materialización de una política que va en contraposición del manejo hacia la transformación del conflicto con miras a un posible avance de las negociaciones. La existencia del mediador del conflicto es necesaria puesto que este conflicto se ha convertido en algo más que una violencia directa, es decir, ha condicionado la solución a causas simbólicas; al mismo tiempo, la existencia del mediador garantiza la neutralidad. El conflicto sobre Jerusalén, dentro del caso israelí-palestino, pareciera ser un conflicto aparte y casi imposible de solucionar, dada la carga simbólica que tiene la ciudad para las dos civilizaciones en conflicto, una carga cultural que no se soluciona simplemente con tomar decisiones que por el contrario pueden afectar la gestión y transformación del mismo.

La histórica participación de los Estados Unidos como mediador del proceso de paz israelí-palestino corresponde a una cuestión muy clara, pues, como lo expresa el investigador palestino, Bichara Khader,

Cuando los Gobiernos árabes quieren que las cosas evolucionen se dirigen a Estados Unidos, a sabiendas de que su política es poco equilibrada. Cuando necesitan financiación o apoyo, entonces sí, recurren a la Unión Europea. Este reparto de funciones traduce, en realidad, la erosión del papel político de Europa, y así lo reflejan los principales diarios árabes. (Ridao, 2011).

Para el caso de Israel, su confianza en los Estados Unidos como mediador consiste en el precepto de que comparten valores político-democráticos que los identifican, claramente en detrimento del papel de Europa en la solución del conflicto, como acertadamente lo menciona Khader en su entrevista. Los Estados Unidos son pragmáticos en su política, propenden por resultados concretos y sólidos; mientras que Europa tradicionalmente ha asumido una política de compromiso de intenciones que la ha situado en un aspecto más emocional que pragmático respecto a este conflicto. 


\section{Identidad y violencia}

La carga simbólica del conflicto israelí-palestino, que se ha transformado a través del tiempo, es quizás la base del mismo. En principio, la disputa por la tierra prometida al pueblo elegido, que alegan ser las dos culturas, generó el reclamo de Jerusalén como capital propia de ambos Estados y enquistó las posiciones de ambas partes afectadas. Por lo que, si el tercero o mediador es quien decide la solución, lo que se espera del conflicto en primera medida es su transformación, de modo positivo o negativo para una de las partes.

Estos dos factores constituyen una estructura de primera fila, al interior del nudo en que se ha convertido la solución del conflicto. Además, ambos han ocasionado que este sea un conflicto de desgaste, precisamente por esa identidad que los dos reclaman sobre la tierra que habitan. Específicamente, el caso de Jerusalén convirtió el conflicto israelí-palestino en un callejón sin salida, al que hoy le sobran propuestas de transformación y solución, aunque ninguna es aplicable desde el punto de vista de las partes en conflicto.

\section{La identidad}

El conflicto israelí-palestino presenta dos formas de identidad, que paradójicamente enfrentan a las partes y al mediador, en este caso, los Estados Unidos. Una primera conjuga la identidad de las partes con la tierra en disputa. En la segunda instancia la identidad de una de las partes en conflicto, en este caso Israel, se conjuga con los valores identitarios del mediador.

\section{a) Primer caso}

Identidad entre las partes en conflicto. Este caso se materializa en la identidad que ambas partes manifiestan tener con el territorio en disputa, dada su historia, cultura y su idea de la misma, es decir, el dominio por esa tierra que ambos manifiestan que les pertenece desde épocas inmemoriales. Esto ha permitido la inamovilidad de posturas en las negociaciones, hecho claramente perjudicial para las pretensiones 
de los palestinos, por cuanto mientras ellos reclaman la posesión de la tierra, pero no avanzan en las negociaciones, los israelíes continúan la construcción de asentamientos, lo cual viene a dificultar aún más la situación. Sin embargo no hay que correr el riesgo de convertir la disputa en un conflicto inmobiliario.

En el caso específico de Jerusalén, el cual por sí solo ya es un conflicto aparte, necesita un debate más realista, en el sentido de la discusión y protección de los valores que representa para unos y otros, por lo tanto conviene analizarlo teniendo en cuenta beneficios y sacrificios para cada una de las partes, sin renunciar a su historia, posición y futuro para ambas partes.

Lo primero, la historia clínica, los antecedentes del conflicto y del enfrentamiento. No es quedarse definitivamente en ellos, ya que pueden ser innecesarios para el objetivo pretendido, pero sí es bueno tenerlos en cuenta. En segundo lugar, los enfrentamientos suelen tender a ocultar aspectos de los mismos que son particularmente importantes para entender lo que sucede y las posibilidades (si es que las hay) de incidir positivamente en los mismos. En tercer lugar, los enfrentamientos no suceden en las páginas de los periódicos o en las de los informes académicos, sino en contexto muy reales de los que adquieren su tonalidad particular y lo hacen totalmente diferente de cualquier otro. Finalmente, conviene saber el grado de internacionalización que tiene el enfrentamiento y la eventual presencia extranjera (económica, logística, política o incluso militar) en el enfrentamiento en cuestión. (Tortosa, 2008).

Esta identidad cultural de ambos pueblos con la misma tierra, los antecedentes, el alcance global del mismo y sus consecuencias, lejos de acercar a las partes durante este último periodo, ha congelado cualquier perspectiva de solución del mismo.

\section{b) Segundo caso}

La identidad de una de las partes con el mediador, es decir entre los Estados Unidos e Israel, cuyos valores estructurales como sociedades 
democráticas occidentales son compartidos. Su cultura, basada en la religión judeo-cristiana, no solo identifica a ambos países sino a sus sociedades, de tal manera que tanto en lo político como en lo socio-cultural ambos países son afines.

El aspecto democrático, por sí solo, hace que la geopolítica sea el punto común de unión entre los Estados Unidos e Israel. La democracia como sistema de gobierno identifica a Occidente, de ahí que cuando el presidente Obama afirma que el apoyo de los Estados Unidos hacia Israel es inquebrantable, hace referencia a la forma de vida que los une. Así también lo entendió George W. Bush, pues expresó que «el terrorismo quiere cambiar nuestra forma de vida», hacía referencia al sistema democrático y los valores que este representa.

La identidad entre los Estados Unidos e Israel, junto con su relación, no consiste en el entramado oculto que muchos han idealizado; la unión de estos Estados se da a partir de los valores democráticos occidentales que unen a las instituciones políticas, académicas y a todo un escenario cultural. Israel se erigió en un espacio donde históricamente no ha primado la democracia, pero, en cambio, la identidad democrática de los fundadores del Estado hebreo y su instauración al momento de su fundación han identificado a los dos países desde el presidente Truman hasta hoy, aunque esto no ha sido óbice para que en determinados períodos haya habido momentos álgidos.

Con todo, hay que agregar el aspecto geoestratégico que no es menos importante dentro de la relación. En este sentido, los intereses de Estados Unidos en la región son punto sensible de su seguridad, por lo que Israel contribuye a garantizar que esos intereses estadounidenses confluyan en la seguridad de ambos países. Podemos tomar como ejemplo la cuestión de Irán. Actualmente, para los Estados Unidos no es viable que un país hostil hacia Occidente adquiera una bomba atómica; Israel también comparte esa preocupación pues ve amenazada su existencia, dadas las constantes diatribas expresadas por el régimen iraní hacia Israel. Encontramos entonces que ambos países comparten toda una serie de premisas, por lo que hacen de ello toda una construcción universal de valores político-culturales occidentales que se han desarrollado en una relación simbiótica entre ambos Estados. 
Cuando hablamos de culturas dentro del conflicto israelí-palestino, nos referimos al simbolismo, a la identidad de ambas partes con respecto a los territorios en disputa, porque el simbolismo representa identidad, y la identidad, parafraseando a Samuel Huntington, no solo se descubre hacia el futuro sino también en el pasado, de allí que puedan surgir guerras con enemigos nuevos pero también con viejos. Ese es un aspecto de la cultura que prácticamente no ha sido tenido en cuenta en las distintas negociaciones, por temor seguramente a que se le reivindique como un conflicto religioso y haga más compleja la resolución. Lo anterior, a pesar de que la religión hace parte de los aspectos específicos que forman una cultura y que la diferencian de las demás, es decir, idioma, religión, arte, historia e incluso territorio, en el caso del conflicto israelí-palestino.

Introducir la cuestión cultural como teoría es absolutamente pertinente, por cuanto el conflicto no solo está impregnado de simbolismo sino también porque cada una de las partes es representativa de una cultura, e incluso una de ellas (Israel) es principio y origen de la occidental. La carga simbólica de los lugares santos, ubicados en los territorios en disputa (dentro de Jerusalén), hace que este conflicto sea más fuerte que cualquier otro en el mundo, de ahí que este sea el único que hoy pervive después de seis décadas. Este es un aspecto que no se puede pasar por alto en las negociaciones de paz y mucho menos por la clase política no solo de ambos lados sino también del mediador.

La cuestión identitaria no puede apartarse de este conflicto, pues es el único que aún pervive por esta causa; además se debe tener en cuenta que una de las partes es una democracia, al igual que el tercero mediador, pero que no ocurre lo mismo con la otra parte. En consecuencia, no es posible aplicar una política de cooperación que pretenda que la identidad entre las partes sea la misma y que por tanto se puede aplicar una paz creíble y duradera. Esta cuestión tiene que ver con la historia y cultura de estos dos pueblos, lo que ha generado que esa misma cultura genere violencia.

En los conflictos de gran proporción, la violencia directa que proviene de la cultura tiende a cambiar según las circunstancias, es decir, según el avance técnico científico, por lo que la humanidad encontrará nuevas formas de materializarla. 
Una primera idea de violencia, en un sentido amplio, se refiere al daño ejercido sobre los seres humanos por parte de otros seres humanos. Una segunda idea de violencia, es el resultado de la interacción entre la agresividad natural y la cultura. Es decir, violencia es cualquier acción (o inacción) realizada a otro ser humano con la finalidad de causarle daño físico o de otro tipo, sin que haya beneficio para la eficacia biológica propia. Lo que caracteriza a la violencia es su gratuidad biológica y su intencionalidad psicológica (Jiménez, 2012).

La violencia, como acto lesivo del hombre contra el hombre, siempre ha estado en el contexto humano y por ello se han desarrollado los conflictos, las luchas por el poder, por el dinero, por la supremacía o la supervivencia; en síntesis, podemos observar violencia en cualquier momento y lugar donde nos encontremos. No es algo de lo que el ser humano haya podido prescindir en su entorno, como tampoco podemos afirmar que por esa razón sea necesario conformarse y decidir vivir con ella.

Se debe entender que el ser humano no es perfecto ni mucho menos una máquina exacta, sino un ser biológico, o, si se quiere, una máquina biológica; eso lo hace susceptible de cambios que lo llevan a cometer errores. De igual forma, ese ser biológico tampoco es un ser homogéneo en su entorno, no es un ser aislado y tampoco tiende a ello, por lo que culturalmente debe interrelacionarse. Y, dentro de dicha interrelación, es normal que se presenten actos de violencia y no por ello podemos afirmar que el hombre es violento por su naturaleza humana, pues tampoco todos los hombres lo son.

La cuestión de la violencia ha acompañado al hombre en todos los periodos de la historia, desde que en un principio luchó por su supervivencia hasta hoy; y las razones, como he mencionado anteriormente, suelen ser por diversos motivos, pero nunca podremos estar de acuerdo con quienes han teorizado que la violencia es innata en el ser humano o es exclusiva de una cultura en particular. No es posible, al analizar el conflicto israelí-palestino, afirmar que los israelíes o que los palestinos son violentos, pues esto, además de ser una falsa etiqueta, constituye una injusticia. 
El investigador Jiménez Bautista, cita el artículo de Hanna Aren$\mathrm{dt}$, Conocer para comprender la violencia: origen, causas y realidad, para afirmar lo siguiente:

Hanna Arendt realizó un estudio (Arendt, 2005) sobre las bases teóricas de la violencia, concluyendo que la violencia es la expresión más contundente del poder y que surge de la tradición judeocristiana y de su imperativo conceptual de Ley. En este sentido, la violencia se enraíza en lo más profundo y original de nuestra sociedad occidental, esto es, en los principios más antiguos que fundaron nuestro pensamiento. (Jiménez, 2012).

No estoy de acuerdo con este planteamiento de Arendt ni con su utilización como base para definir la violencia. Si bien el hombre, en su imperfección, es susceptible de converger en conflictos y desarrollar la violencia; no es menos cierto que dicha violencia tampoco es exclusiva de una cultura determinada. Los primeros habitantes del planeta no pertenecieron a una cultura que podamos etiquetar en los espacios de hoy día, sin embargo el hombre luchó con violencia, de igual forma la enfrentó para lograr sobrevivir.

Así mismo, es inaudito e injusto etiquetar a la cultura occidental o a la civilización judeocristiana como exclusivos creadores de la violencia, pues antes de esto tendríamos que hacernos preguntas como ¿dentro de qué tipo de acto tendríamos que situar los atentados terroristas del 11 de septiembre? Es un hecho que estos fueron actos de violencia que causaron un conflicto bélico en respuesta a los mismos. Además, estos actos terroristas no fueron planeados ni ejecutados por ciudadanos occidentales y tampoco eran practicantes de la religión judeocristiana, en cambio, pertenecían a países árabes. ¿Cómo explicaríamos entonces los actos de Pearl Harbor por parte de los japoneses siendo estos asiáticos y no occidentales? Tal vez tendríamos que concluir diciendo que, por ser estos actos de violencia ejecutados por ciudadanos no occidentales, entonces no se consideran terroristas.

Tampoco es aceptable la utilización de la ley como supuesto presupuestario para justificar la violencia, por el contrario, es la misma 
ley la que se opone a que se causen actos de violencia de cualquier magnitud y para esto ha sido creada. Lo que se contempla en la ley son excepciones al rompimiento de la misma, los cuales deben conllevar una sanción. Las distintas culturas están impregnadas de valores, que las hacen distintas unas de otras y esa es nuestra naturaleza, lo cual nos da pie para rechazar toda investigación que pretenda concluir con la afirmación de que una cultura determinada es propietaria exclusiva de la violencia.

La ley es de carácter obligatorio, es decir, en tanto sea violada tendrá un carácter sancionatorio pero no represor, por lo que no es posible armonizar su contenido dentro de una sociedad o una cultura como algo que se utiliza para la agresión de los pueblos. La ley, según Santo Tomas, es «una prescripción de la razón, en orden al bien común, promulgada por aquel que tiene el cuidado de la comunidad» (Ruiz, 2011). Para su eficacia la ley debe ser promulgada, promoviendo que su desconocimiento no sea excusa para su violación. Por lo tanto, si la ley transnacional es violada, son los organismos internacionales (por ejemplo, Naciones Unidas) quienes están en la obligación de imponer la sanción, no por ello es exclusiva de occidente ni su carácter es imperativo de conflicto.

Este libro tiene como base constante la posibilidad de la paz, es este caso, con énfasis en la transformación de un conflicto determinado, pues la naturaleza humana hace al hombre prolijo en la innovación para su supervivencia, el medio ambiente diseña al hombre, influye en él, por lo tanto él es susceptible a los cambios que en su entorno sucedan. De tal forma que los actos de paz o de violencia del hombre están determinados por la naturaleza que lo rodea, por su naturaleza, esa que le emplaza a compartir espacios, costumbres, valores y que le impide vivir aislado.

En el conflicto israelí-palestino hay hechos que hacen que este sea excepcional, por ejemplo, que este está impregnado de un carácter cultural en sus factores endógenos y exógenos. Este hecho ha propiciado -como he mencionado anteriormente- que se genere una violencia directa, que a su vez materializa un choque regional de civilizaciones.

La violencia no siempre genera un conflicto. Para ejemplificar este punto de vista, podríamos mencionar a una persona que ejecuta un 
acto de violencia contundente (quitarle la vida a otra); pese a la gravedad, este hecho no genera un conflicto entre las partes, puesto que uno de los dos cortó la relación víctima y victimario que pudo haberse generado; sin embargo cuando la violencia toma otras magnitudes entonces sí genera un conflicto. El conflicto en sus esferas más altas tiende a generar innovación, que en este ámbito degenera en destrucción; además, en estos casos se desarrolla una cadena en la que el hombre se emplea en distintos escenarios.

Hay quienes ven en el conflicto una oportunidad de crear una relación laboral, por ejemplo, mediante la puesta en práctica del desarrollo de la tecnología y la innovación de nuevas armas e instrumentos para el combate, es decir con la industrialización de la violencia, se produce el escenario propicio para que algunos puedan enriquecerse o aumentar su riqueza. El conflicto también es la oportunidad perfecta para la utilización de nuevas armas, por lo que la población civil o militar se convierte en campo de pruebas; de igual forma se prueban nuevos medicamentos sobre civiles y militares. Todo esto ocurre bajo la utilización de la violencia como oportunidad de desarrollo tecnológico.

Esta última tendencia depredadora -en la que se supeditan las «necesidades de los seres humanos» de todo el entorno- ha llegado a alcanzar a la propia especie (matanzas, explotaciones, contaminación, colonialismo e imperialismo o discriminación de género, entre otros), de tal manera que poblaciones enteras sufren por las decisiones de sus congéneres e, incluso, podría existir peligro de supervivencia para el conjunto de la misma (terrorismo, guerra nuclear, etc.). Kart Popper planteaba que la cuestión fundamental de cualquier organización democrática es cómo organizar las instituciones políticas de forma que los malos y los incompetentes gobernantes no puedan provocar en ellas daños excesivos e irreparables. (Jiménez, 2012).

El conflicto, sin embargo, puede llegar a desarrollar una universalidad de oportunidades a través de las cuales los antagonistas logran socializar mucho más de lo que nosotros podemos sospechar desde 
afuera, pues la necesidad de entendimiento para su transformación y solución hace que el acercamiento de las partes sea requisito indispensable para el consenso, y el conflicto israelí-palestino no es la excepción.

\begin{abstract}
El conflicto en sí mismo ya es una resolución de la tensión entre los contrarios; el que pretenda la paz, no es sino una expresión particular y obvia, del hecho de ser síntesis te elementos, ya sea contra otro o con el otro, bajo un concepto superior [...] El conflicto es, sin embargo un hecho sui generis, y subordinarlo al concepto de unidad resulta tan forzado como vano, toda vez que significa la negación de la unidad. (Simmel, 2010).
\end{abstract}

La necesaria socialización entre las partes, a la cual conduce el conflicto, no ha sido, en el caso del conflicto israelí-palestino, un factor de unidad o aceptación del otro, por el contrario, como afirma Simmel, ha sido, a pesar de esa socialización, el rompimiento de la relación que ha traído consigo la destrucción de la unidad, si es que una vez la hubo. La responsabilidad de mantener viva esa socialización ha recaído sobre los Estados Unidos, y en ocasiones también sobre Europa y algunos países árabes, pues estos últimos han influido para que esa socialización no se rompa.

Sin embargo, esa necesaria socialización del ser humano con su antagonista no está exenta de interrupción. Cuando el diálogo se agota, o las partes se muestran estériles al mismo, no queda más que esperar como resultado el final de dicho diálogo y la continuidad del conflicto. Esto es lo que hoy se observa dentro del conflicto israelí-palestino, un rompimiento de la unidad dentro del diálogo, una negación del otro, que han traído como resultado la unilateralidad de una de las partes como única vía para la transformación y solución del conflicto.

Se diseñó un marco de perspectiva holística del conflicto, en virtud de todos los fenómenos que convergen dentro del mismo y que hacen que este abarque no solo la violencia sino la paz y sus distintos tipos, todo lo que estas dos situaciones implican en ambas sociedades, el conflicto se transforma, a veces intencionalmente a veces por 
el tercero mediador o por razones exclusivamente externas e independientes al mismo.

El universo que abarca el conflicto es una constante de disentimientos, que afecta a las sociedades, gobiernos y Estados, pero que al mismo tiempo se mueve dentro de la unidad que genera la necesidad del diálogo. Al interior de ese universo encontramos la dualidad de la sociedad que propende por la superioridad sobre el otro. Tal y como afirma Simmel, "que el conflicto tiene relevancia sociológica, por cuanto genera o modifica comunidades de intereses, unidades y organizaciones, no es algo que se ponga en duda» (Simmel, 2010).

El conflicto israelí-palestino, marcado por la coexistencia de dos pueblos en la misma tierra, ha hecho necesaria la unidad dentro del mismo conflicto, pues la solución depende de que no se rompa dicha unidad, del respeto a las reglas mínimas del conflicto, de no caer en la unilateralidad de las partes; pues aunque exista el antagonismo, sinónimo de dualidad y de estado de normalidad dentro del conflicto, es necesario propender por la unidad dentro del diálogo.

\section{Violencia cultural}

Este tipo de violencia se justifica sobre la base de lo que pertenece a unos y a otros no. En el caso del conflicto israelí-palestino, la cultura y el origen de su civilización plantea una diferencia para los pueblos, que puede ser entendida a partir de los planteamientos de Jiménez, cuando afirma que,

Si la violencia directa es generada desde el propio agresor y la violencia estructural está organizada desde el sistema -la estructura-, la violencia cultural lo hace desde las ideas, las normas, los valores, la cultura, la tradición, etc., como alegato o aceptación «natural» de las situaciones provocadas por ella. Es decir, todo aquello que en definitiva desde la cultura legitime y/o promueva la violencia de cualquier origen o signo. (Jiménez, 2012).

Dentro del conflicto, esta causa impregna todo el medio ambiente. En consecuencia, la actitud irreconciliable que ambos pueblos 
manifiestan al momento de llegar a un acuerdo tiene su origen en el aspecto cultural, como puede ser Jerusalén o la tierra misma. Ambas partes miran sus intereses basados en la cultura que se manifiesta en símbolos tangibles (representativos de cada pueblo) y cuya base se halla mayormente en la religión.

Con base en lo anterior, podemos decir que Israel defiende el carácter de Jerusalén como su única capital, ya que allí estuvieron el Primer y Segundo Templo. Ahí están sus ruinas. Al mismo tiempo se niega a elevar la ciudad al carácter de tratamiento internacional. Lo mismo ocurre con los palestinos, para quienes en Jerusalén fue donde «el profeta habló por última vez. Desde allí subió al cielo», allí está la mezquita de Al Aqsa. En síntesis, el trabajo de reconciliación de estos dos pueblos, que tiene culturas totalmente distantes y distintas, corresponde en gran medida al mediador, aunque esto no significa que también le corresponda a este último solucionar el conflicto.

Estamos ante un conflicto que se convirtió en un reproche de causas políticas, y cuyos inicios nos retrotraen a las razones identitarias, culturales o civilizatorias. Para los israelíes, la consideración de pueblo elegido los hace incapaz de renunciar a un solo milímetro de territorio dentro de la zona que ostentan, pues toda su historia y cultura, los restos y señas de su civilización -que además es la misma occidental- están allí. Para los palestinos, este territorio es parte de su cultura porque allí el profeta Mahoma subió al cielo; y si tenemos en cuenta que el profeta es el máximo líder del Islam, que es la religión mayoritaria en los territorios palestinos, entonces seremos conscientes de lo álgido de la situación.

Estas no son cuestiones menores ni mucho menos. Estas razones hicieron que en 1946 ambos pueblos se desgarraran en una lucha, literalmente a muerte, por la ciudad de Jerusalén. Esta lucha se produjo porque en este territorio están sus identidades, la historia de sus pueblos y su memoria religiosa; una religión que no solo defienden y practican, sino en la que creen, al punto de ser capaces de dar la vida por ella.

Esta es una zona donde los símbolos culturales determinan la vida de sus habitantes, es decir, es un territorio cargado de un profundo simbolismo religioso. Por otro lado, este territorio ha visto el surgimiento de la violencia cultural, de tal forma que los símbolos antes 
de unir separan. La sola tierra es un símbolo por el que ambos pueblos se han desgarrado por seis décadas; y esta violencia cultural ha formado un cordón umbilical que la conecta inexorablemente con la violencia directa.

\section{Violencia directa}

El escenario de valores histórico-culturales que presenta el conflicto israelí-palestino ha generado, desde su inicio hasta hoy, la materialización de la violencia directa. Este tipo de violencia causa un daño prácticamente indeleble en el cuerpo y la psicología de sus actores.

Es la que se define en espacios personales, sociales y mundiales, y es intencionada, bien por las acciones individuales, bien por personas dentro de colectividades [...] puede dividirse en verbal y física, y en violencia que daña el cuerpo, mente o espíritu. Todas las combinaciones posibles dejan una estela traumática que puede suponer violencia con el paso del tiempo. (Galtung, 2003).

La violencia cultural, que en este caso genera violencia directa, actúa en forma de círculo vicioso, de tal forma que ambos actores acuden a ella para la defensa violenta de lo cultural, que es la base de la disputa. Esta violencia la vimos reflejada en la I y II Intifada y en la respuesta de Israel, en manos de las FDI, las cuales han sido calificadas por la comunidad internacional como desproporcionadas.

Empero, la gravedad de la cuestión, más que su definición, radica en que esta violencia directa, y sus consecuencias, viene a acentuar aún más el conflicto, según sean los actos de un lado y otro; por lo que, tan violentos son los disparos de las FDI contra la población civil como lo fue el secuestro del soldado Gilad Shalid, por parte de Hamas. Debido a las circunstancias y los hechos que se presentan en la zona, la gravedad de esta violencia radica en que ambas partes la justifican como un mecanismo de autodefensa para la protección de lo que consideran sus intereses, que pueden ser reivindicativos de lo cultural, o como instrumento de defensa ante una circunstancia preventiva. 
La violencia directa alimenta el conflicto y la impunidad con respecto al tiempo y al espacio. Al tiempo porque se ha hecho imposible ponerle fin, lo que genera un conflicto de desgaste que no conduce a ninguna parte; al espacio porque lo impregna todo. Aunque hemos de precisar que el espacio se ha reducido a la frontera con Gaza, en donde se han generado consecuencias físicas y psicológicas para sus habitantes, no menos perjudiciales que para los habitantes de los kibutz cercanos a la frontera.

En la década pasada se vivió el punto más álgido de violencia directa durante la operación Plomo Fundido, entre 2008 y 2009. En este periodo hubo bajas de lado y lado, pero dentro de una operación asimétrica, donde es innegable que la más perjudicada fue la población de Gaza. Galtung afirma que la violencia directa es deliberada, intencionada, lo que nos lleva a plantearnos que si la violencia cultural no llega a su fin, entonces la violencia directa que actúa como apéndice de la anterior enrocará más a las partes y llevará el conflicto a continuar siendo un cuerpo que vaga en un limbo de tiempo y espacio indeterminados.

Si la base estructural de este conflicto son los valores, el principio y la historia de dos culturas, podríamos pensar que a través de la paz positiva cultural se puede avanzar en su solución o transformación. En ese caso, «la paz positiva cultural sustituiría la legitimación de la violencia por la legitimación de la paz; en la religión, el derecho y la ideología; en el lenguaje, en el arte y las ciencias, en las escuelas, universidades y medios de comunicación; construyendo una cultura de paz positiva» (Galtung, 2003).

La materialización de la paz positiva cultural, producto del abandono de la violencia directa dentro del conflicto israelí-palestino, pasa necesariamente por el reconocimiento del derecho a existir de dos Estado distintos, en lo que la AP tiene un trabajo interno pendiente que debe llevar a cabo con Hamas, dada su inclinación constante a la negación de Israel como Estado. Esta actitud ha dificultado el fin de la violencia directa y lo seguirá haciendo mientras no se resuelva a nivel de política interna en Palestina.

Sin embargo, no solo la AP debe avanzar en unificar su discurso, su metodología política y sus fines dentro del conflicto, también 
Israel está emplazado a evaluar dentro de qué parámetros es posible la aceptación de Hamas como actor político palestino, lo que le impide a Israel negarlo. Es un hecho indiscutible que Hamas es un actor que genera violencia directa de forma deliberada y constante, así como el hecho de su declaración como grupo terrorista por parte de los Estados Unidos y la Unión Europea; no obstante, en la búsqueda de la paz se hace necesario hacer sacrificios, máxime si son de carácter altruista, y en esta investigación opinamos que Israel debe hacerlos.

Con ocasión del intercambio de presos palestinos por el soldado israelí Gilad Shalid, se pudo observar que sí es posible hacer sacrificios o esfuerzos altruistas en la búsqueda de la paz entre israelíes y palestinos. En este caso se logró poner fin a uno de los actos más repudiables de violencia directa como lo es el secuestro. Si este intercambio fue posible entre Israel y Hamas, es posible también que una futura, aunque no tardía, reconciliación entre la AP y Hamas produzca la unificación de los objetivos, con el fin de conseguir avances sólidos, fiables y ojalá definitivos al cese del conflicto.

\section{Escuelas de pensamiento político internacional}

\section{Realismo político dentro del conflicto}

El papel de los Estados Unidos como mediador dentro de este conflicto corresponde a su supremacía política global dentro de las relaciones internacionales, lo que lo hace capaz de influir en el avance del mismo, es decir, la presencia de los Estados Unidos dentro de las negociaciones de paz equivale a dar ese realismo político que debe acompañar las negociaciones. Dicho realismo político ${ }^{2}$ es totalmente relevante en

2 Ari M Kacowicz, Universidad de Jerusalén. Primacía del Estado, basado en una visión pesimista de las relaciones internacionales, una visión de conflicto, donde hay generalmente y no siempre posibilidades de guerra, los Estados en base a la anarquía en las relaciones internacionales deben basarse en sus propios intereses. 
la política de Oriente Medio, es casi un paradigma, pues está basado en la realidad actualizada de los acontecimientos.

Si el realismo político se ajusta a una situación prebélica, consideramos que la nueva política exterior de los Estados Unidos no es la materialización de esta escuela de las relaciones internacionales, pues proponer hoy la solución del conflicto israelí-palestino con base en las fronteras de 1967 no se ajusta a la realidad. Con base en la realidad actual, no es factible que la zona pueda volver al mapa de hace cuatro décadas; esto no solo es imposible desde el punto de vista del terreno sino también dentro de la identificación social de ambas partes y de su axiología identitaria como nación para cada una de las sociedades que conforman el conflicto.

Dentro del conflicto, el realismo político estadounidense se basó durante décadas en la situación de seguridad y protección de intereses en la región, lo que materializó una política exterior regional paradigmática para un lugar específico del globo. Mencionamos la palabra paradigma pues ningún otro conflicto se ha gestionado de la manera en que se gestionó el conflicto israelí-palestino; tampoco ha sufrido las transformaciones o mutaciones que este ha sufrido durante seis décadas. Esas mutaciones han ocurrido precisamente porque las circunstancias en la región están en un continuo cambio. Aunque parezca que el conflicto no avanza, lo que ocurre es que se transforma, y esa transformación ocurre porque surgen y desaparecen actores exógenos y endógenos que tienen o han tenido influencia sobre el mismo.

De esta forma, Estados que en un momento dado fueron claves dentro de la solución al conflicto, luego pueden no serlo, tal es el caso de Egipto y Jordania (Transjordania en el pasado), que pasaron de ser actores endógenos a exógenos. Otro ejemplo sería Hamas, quien antes de 1987 no existía pero hoy se ha convertido, quizá, en uno de los factores más desestabilizadores para la consecución de la paz. Lo mismo ocurre con líderes políticos que en su momento han gobernado para ambas partes del conflicto, o líderes políticos estadounidenses que han actuado de forma exógena como terceros mediadores.

Todos los actores mencionados anteriormente y otros, han hecho del realismo la base estructural de este conflicto; sin embargo ese realismo nunca impuso una solución, y si hoy no se ha logrado la solución 
del conflicto es precisamente porque el mediador ha respetado las propuestas a la solución del mismo que han venido de ambas partes. Bajo este panorama, es necesario preguntarnos ¿por qué se insiste hoy en que los Estados Unidos desequilibra la balanza a favor de Israel? Algunos argumentan que es porque permite la extensión de los asentamientos. Y acá es importante recordar que todos y cada uno de los presidentes estadounidenses han condenado este hecho cada vez que ha sucedido, de la misma forma que han condenado el lanzamiento de cohetes desde el lado palestino.

Aunque los Estados Unidos siguen condenando los hechos hostiles de unos y otros, es un hecho que si bien su estrategia permanece intacta lo que ha cambiado es la táctica para conseguir la posible solución del conflicto. Es un hecho que los Estados Unidos, por compartir valores occidentales, no llegarán a una confrontación en cuanto a sus relaciones Estado/Estado, pero también es un hecho que esto no ha impedido que la administración Obama haya cambiado la táctica de cooperación de los Estados Unidos dentro del conflicto, como también que haya dejado claro desde dónde se debe empezar a negociar; hecho inédito que ha sorprendido no solo a las partes del conflicto sino a la comunidad internacional.

Pero, sobre la base de la imposición de un proyecto, ¿es posible conseguir la paz entre palestinos e israelíes? Pensamos que no, pues son las partes y no el mediador quienes deben llegar al consenso, aunque unos y otros tengan que hacer concesiones dolorosas para sus sociedades e incluso sus culturas. Lo paradójico es que mientras los Estados Unidos cambiaron su política exterior en Oriente Medio, de igual forma la AP dio un giro y empezó a trabajar por la solución al conflicto desde arriba, contrario a lo que venía haciendo décadas atrás y de paso utilizando el realismo político para sustentar su nueva política exterior.

\section{Constructivismo político}

Actualmente, la cooperación de los Estados Unidos dentro del conflicto está basada en un paradigma regional de constructivismo, es decir, no hay apego a la realidad sino que se pretende construir una sobre la base de tesis que no son susceptibles de ser entendidas por ambas 
partes involucradas en el conflicto. Sin embargo, la nueva política exterior de los Estados Unidos cree que, desde el punto de vista de las fronteras de 1967, esa axiología identitaria sí es posible, de tal forma que estamos hablando de la escuela política del Constructivismo, que aunque no es una escuela de las relaciones internacionales sino que es importada de la Sociología sí se aplica a las mismas.

Dentro de las relaciones internacionales, Estados Unidos ha dado el salto del realismo político a este constructivismo dentro del conflicto; $y$, aunque en esta investigación hemos afirmado que no es posible obviar la identidad de las partes, no por ello opinamos que deba ser la base estática sobre la que gire la solución del conflicto. Aunque el constructivismo se afirma en la identidad y las normas entre Estados, este no aplica para israelíes o palestinos, a pesar de que históricamente han compartido el mismo territorio con los mismos lugares simbólicos. La identidad entre los Estados Unidos e Israel es indiscutible, no así entre los Estados Unidos y palestinos, por lo que no se entiende del todo la aplicabilidad del constructivismo dentro del conflicto.

Las partes de este conflicto no comparten una identidad común y esto ha hecho que la posibilidad de su solución conlleve un conflicto de desgaste. El hecho de no compartir una identidad política también genera un conflicto como el actual. En resumidas cuentas no es imposible trabajar sobre una transformación del conflicto que desemboque en la materialización de la paz, algo que para el realismo político sería ideal pero no para el constructivismo que hoy rige las relaciones internacionales regionales.

La realidad es mucho más heterogénea de lo que se piensa, por lo que dentro del conflicto israelí-palestino no es posible aparcar ninguna de las concepciones históricas, tanto antiguas como recientes, de cada una de las partes. Son estas realidades políticas las que deben ser abordadas desde la perspectiva de la paz, pero no de una paz estática, inmóvil, sino de una paz dinámica que aporte al desarrollo de un futuro Estado palestino y contribuya igualmente a la seguridad del Estado de Israel y por ende a las relaciones pacíficas entre ambas partes.

No menos preocupante es la premisa de «tierra por paz» que menciona la administración Obama. Esta es equivocada y perjudica la transformación del conflicto, en tanto que la realidad política no 
permite establecer la constante de que los conflictos en Oriente Medio van a desaparecer con la solución del conflicto israelí-palestino. De tal forma que la seguridad del Estado de Israel no es susceptible de ser garantizada mientras la realidad política de la región sea la actual: un Irán nuclear, una Siria hostil y un Irak que se presenta como una incógnita.

La premisa de que la solución del conflicto israelí-palestino traerá la paz a la región es, por lo menos, una falsedad en cuanto al aspecto geopolítico, pues existen sendos ejemplos dentro del mismo proceso de paz que demuestran que no es cierto. Véase la desconexión de Gaza por parte del Estado de Israel en 2005, durante el gobierno de Sharon, y cómo desde entonces no han cesado los roces en la zona ni ha dejado de incrementarse la violencia directa entre ambas partes. Otro ejemplo es el intercambio de secuestrados israelíes por presos palestinos, que tampoco ha hecho que cese la violencia; de tal forma que, en nuestra opinión tal vez, no es realmente necesario trabajar en una resolución del conflicto sino más bien sobre la transformación del mismo.

La resolución del conflicto exige la inmediatez para poner punto final al mismo, por lo que no es aplicable a los conflictos bélicos, como bien indica Vicenç Fisas: «[...] son engañosas y destinadas al fracaso las ideas que pretenden trasladar al campo de los conflictos internacionales o a las guerras internas, fórmulas de regulación que son propias de los conflictos domésticos, no obstante se puede aprender mucho de ellas» (Pax, 2011).

Sobre la base de que no todos los conflictos son iguales, tampoco su tratamiento es el mismo, de tal forma que la política estadounidense errática en su práctica dentro del conflicto ha causado que éste se haya extrapolado a escenarios multilaterales, lo que ha ocasionado que efectos bilaterales causen daño a nivel global. Desde el inicio de las negociaciones en 2009, la actual política exterior de los Estados Unidos frente al conflicto israelí-palestino no ha hecho más que profundizar y polarizar las posiciones de unos y otros.

En general, en este conflicto las partes reclaman como legítimas únicamente sus aspiraciones, lo que conlleva que cada una piense que solo su aspiración es legítima mientras que la del otro no. En este sentido, es ostensiblemente errático que el mediador sea quien se erija, en lugar de árbitro, como la persona que cree tener la solución. Esta 
situación se ha presentado en este periodo presidencial de los Estados Unidos, en cuyo caso no es posible entender que el presidente estadounidense afirme que se debe negociar sobre la base de las fronteras de 1967, pues de forma automática está deslegitimando las aspiraciones de una de las partes que se opone a negociar sobre esa base.

El mediador, en este caso el presidente de los Estados Unidos, ha encallado en su política de solución del conflicto israelí-palestino, pues ha permitido que las partes lleguen a un punto prácticamente irreconciliable, lo que ha desembocado en una situación de desafío de la AP a la administración estadounidense en los escenarios multilaterales, como hemos visto en los últimos meses.

Pese a la petición (en principio) y ahora advertencia de parte de la administración estadounidense a la AP de frenar sus aspiraciones dentro de la ONU y sus organizaciones, esta ha continuado con su política diplomática unilateral, ocasionando que la administración israelí haga lo propio. En pocas ocasiones el conflicto se había polarizado de tal forma.

Lo que se busca es una paz sólida y creíble como salida al conflicto, lo que de hecho no es garantía de paz sostenible o duradera. Es necesario trabajar en la transformación del mismo sobre la realidad política de la región, porque la solución del mismo no tiene por qué ser positiva, en el sentido de que deje satisfecha a ambas partes. Hemos mencionado anteriormente la premisa tierra por paz, ofrecida por la AP a Israel, pero nos preguntamos ¿es real garantizar esta propuesta por parte de la AP? Es evidente que los israelíes no han creído fiable esta propuesta, pues no ven un futuro Estado Palestino como un gobierno influyente al punto de poder moldear la política de conflictos en la región, no podemos por tanto creer que un hipotético Estado Palestino pueda influir en la política de seguridad iraní.

La política exterior de los Estados Unidos en la administración Obama ha resultado infructuosa en la tarea de transformar el conflicto y enderezar el camino. En primer lugar, hemos de decir que la AP ha cambiado su táctica, aunque no su estrategia, pues ahora ha decidido presionar el fin del conflicto desde arriba como nunca antes lo había hecho, y no desde abajo como históricamente se venía haciendo desde los inicios del mismo. 


\section{La búsqueda de la solución desde abajo}

Históricamente el conflicto israelí-palestino se ha administrado, manejado o gestionado desde sus propios líderes con la única intervención externa de los Estados Unidos como mediador y Egipto y Jordania como observadores de las negociaciones. Este fue el paisaje con el que se encontró el presidente Obama a su llegada al poder y era el que se había materializado en las distintas negociaciones, tal como lo hicieran sus predecesores.

La constante de llevar las negociaciones y buscar la solución desde abajo ha llevado a ambas partes a ejecutar actos de forma unilateral para la búsqueda de la solución del conflicto. Desde abajo, no siempre estos hechos han sido de forma pacífica, aunque sí algunos, pues ambas partes han llegado a ejecutar actos hostiles en busca de poner fin a lo que cada uno entiende como amenaza.

Algunos actos realizados en la búsqueda de la paz desde abajo dentro del conflicto israelí-palestino, o incluso por transformar el mismo, han consistido en el intercambio de secuestrados israelíes a cambio de presos palestinos, como últimamente acabamos de ver con el caso del soldado Guilad Shalid, liberado por Hamas a cambio de la liberación de 1027 presos palestinos. Este fue un acto de paz que significó un pequeño avance dentro de la compleja situación que se vive en Gaza, pero que visto desde el aspecto político para unos fue un fracaso y para otros un éxito.

Este hecho es un claro ejemplo de cómo los dos sectores palestinos (Fatah y Hamas) han negociado durante años con los distintos gobiernos israelíes y con la participación de terceros países de la región como garantes, de tal forma que han podido llegar a estos acuerdos. La negociación desde abajo ha consistido históricamente en el cara a cara de los líderes de ambas partes, así ocurrió con Arafat con Rabin, Netanyahu, Barak, Sharon, Olmert y nuevamente Netanyahu en los últimos años, del mismo modo que hasta hace poco se venía negociando entre Abbas con Olmert y Netanyahu. Es decir, siempre existieron las negociaciones cara a cara.

Creo más coherente apostar por la solución del conflicto desde abajo, pues en ella participan directamente los implicados, y, dado que 
es su responsabilidad, deberán necesariamente elegir cuáles son las posibles vías que despejarán el camino hacia la paz, en un ambiente donde la cultura sea un aporte y el hilo conductor, y no la causa del conflicto, para ello las fronteras culturales entre unos y otros se deben neutralizar a favor de la negociación. El inicio de materialización de la paz en el conflicto debe llevar consigo una transformación anterior a la solución.

Se hace hincapié en esto último porque, históricamente, hemos observado que las negociaciones no han conducido a nada. Salvo los puntos en que convergieron las partes y los garantes dentro de los acuerdos de Oslo, no se ha avanzado porque se han puesto en primera fila los puntos más sensibles del conflicto; tal vez si se hubiera sensibilizado a ambas sociedades en la necesidad de una solución negociada hoy estaríamos trabajando sobre otro aspecto. Tampoco hemos observado a representantes de la sociedad civil de ninguna de las partes participando de las negociaciones, por lo que creemos que la participación de un representante por cada sociedad podría ayudar a avanzar sobre todo en la sensibilización de la necesidad de conseguir avances concretos.

En ocasiones, el gobierno del primer ministro israelí ha mencionado la celebración de un referéndum en Israel para que la sociedad decida sobre las fronteras, o el estatus de Jerusalén, pero esto es demasiado complejo; es más inteligente insistir en la participación de ambas sociedades, a que esto consista en una simbiosis en la mesa de diálogo, en la que puedan conversar unos y otros. Cuando hablo de una salida al conflicto desde abajo, me refiero a lo que tradicionalmente ha ocurrido desde arriba a nivel regional, pero que a nivel internacional consiste en negociaciones desde abajo, pues son los directamente implicados en representación de sus instituciones que han liderado las negociaciones.

$\mathrm{Y}$, aunque sugiero la búsqueda de la paz dentro del conflicto israelí-palestino desde abajo, uno de los errores que no ha permitido el consenso de las partes y por el contrario ha exacerbado el ánimo de las mismas es la pretensión de negociar al inicio los puntos que ambas partes consideran irreconciliables, por ejemplo, el estatus de Jerusalén que, en mi opinión, debe abordarse como último tema de la negociación. 
Existen puntos tanto o más urgentes de solucionar, por ejemplo, la distribución del agua en la zona, o el cruce de los puntos fronterizos que hace más lenta la vida en el territorio, sobre todo para los palestinos que necesitan los servicios que no tienen y que deben pasar a Israel para obtener (salud y educación). Es un hecho que, de los dos, Israel es quien más tiene para aportar al avance de la sociedad palestina, por esa misma razón la necesidad de la sensibilización de ambas sociedades juega un papel preponderante: para los palestinos sería una ganancia, para los israelíes puede transformarse en seguridad. 